\title{
Design and Practice of Virtual Simulation Experiment Teaching Center for Modern Enterprise Business Operation
}

\author{
Zhang Liucheng \\ Harbin University of Commerce, Harbin, China \\ zhangliucheng@126.com
}

Keywords: experiment, center, operation

\begin{abstract}
In this paper, in order to improve students' innovative spirit and practical ability, we design the basic framework of virtual simulation experimental teaching center of modern enterprise business, and build the teaching resources platform consists of platform, experimental teaching resources and teaching management platform and network information platform. By constructing modern enterprise business operation environment, modern virtual simulation module enterprise business operation and management of virtual simulation module and integrated practice of modern enterprise business virtual simulation module. Students are personally on the scene pre internship, work contents and characteristics of cognition and knowledge of modern commercial society of internal and external organizations, different occupation. In the basic of mastering the basic business processes and methods and the system training, improve students' comprehensive implementation ability, comprehensive Strategy ability, cultivate students' awareness of cooperation, team spirit and improve students' comprehensive practical ability and innovation ability.
\end{abstract}

\section{Introduction}

In order to meet the needs of practice teaching re-form in economic management, we take effective measures to mobilize the enthusiasm of all aspects, carry out the reform of experiment teaching, improve the teaching system, improve the experimental teaching method, and give full play to the important role of experimental teaching in the cultivation of talents. Not only strengthen economic management practice teaching connotation construction, but also actively carry out the virtual simulation experiment teaching construction. At present, the virtual simula-tion experiment center of business operations of modern enterprise is mainly responsible for the vir-tual simulation experiment teaching task of 21 un-dergraduate students in 8 teaching departments, such as management college, College of accounting, economics, finance, finance and public management.

Center opened 33 virtual simulation training courses and experimental project is more than 200 items. These results can make the full realization of the business activities which include enterprises in the simulation for operation and management and external ecological environment simulation training. The basic teaching resources of the center are divided into three functional modules: the modern enterprise business operation environment virtual simulation module, the modern enterprise business operation management virtual simulation module and the modern enterprise business operation comprehensive practice simulation module. The center of the three major functional modules, respectively, correspond to the professional training platform, comprehensive exercitation platform and comprehensive practice platform to train students with different levels of ability.

\section{Virtual simulation module design for business}

Operation environment of modern enterprise Any enterprise is living in a specific ecological environment. Enterprise ecological environment is a very complex system, in order to show the students a clear display of modern enterprise business environment, the center design the modern enterprise business operations of the ecological environment of virtual simulation module from three 
levels.

Supply chain panorama simulation. The module corresponds to the supply chain of actual combat simulation course, including supplies chain accounts, sales management, purchasing management, inventory management, inventory accounting, contract management, sales analysis and other experimental projects. Students in the learning process take the role of suppliers, manufacturers, distributors and retail terminals, so that students can experience the business collaboration among suppliers, core production or service enterprises, distributors and third-part logistics enterprises. In these way, students can feel the environment and process of enterprise survival and development, understanding the right business ideas and management concepts, and more profound experience in the supply chain competition. Through this module, the students can understand the basic process of building, equipment and process of materials sales, understand the skills and methods of customer negotiation and signing contract, understand the basic knowledge and methods of the gathering management, understand the basic process about merchandise procurement of the client company, and understand the skills and methods of the bank transfer and payment.

Public service agency simulation. This module which is real simulation mainly includes the industry and commerce, taxation, social security and other government agencies and banks, accounting firms, law firms, the company's human resources, recruit tender center, exhibition center and other public service agencies. By using the module, realize the multi organization, multi industry simulation and commercial form against, and finally, achieve a panoramic view of the modern business operation simulation training. The module uses the government service agency simulation system and the public service system simulation system, and sets up the business training. In industrial and commerce bureau, business training in tax bureau, banking business training, business training in social security bureau, business training in accounting firms, business training in law firms, and other business training courses. Through the training of this module, students can experience the influence of financial, taxation, industry and commerce, accounting firms, exhibition and other public services on business management activities, and understand the process of the corresponding public services and the various materials and forms needed, training students to engage in basic skills of related work.

\section{Modern enterprise business operation management simulation module design}

According to the law of modern enterprise management, this module includes six sub modules and a comprehensive training module.

Entrepreneurial training module.The module corresponds to the business simulation courses, including the industrial and commercial registration, business plan design, marketing creation and promotion, human resources management, enterprise financial management and other experimental projects. Through the simulation of various business links, students can understand the process of entrepreneurship, so that students can establish a three-dimensional understanding of the entrepreneurial behavior, understand the core business rules, dynamic matching, the various key business links, and develop the right sense of entrepreneurship.

Business decision training module.The module includes business decision-making practice and enterprise commercial combat simulation program. These courses consist of production and plant management, OEM market decision, own brand decision-making, financing and financial management, enterprise resource planning, enterprise management decision, marketing sales experiment, corporate restructuring, and other experimental projects. By drawing up some plans, including the development of enterprise strategic plan, market and competitor analysis, marketing sales plan, market development plan, annual production plan, purchase plan, financing plan, transform the work plans from digitalization to the finance indexation and ensure that the business plan is connected with the annual target. Through this module, the students can understand the content of strategic decision-making, the convergence and development process of various kinds of plans, training students' global consciousness and system thinking ability and decision-making ability. 
Operation management training module .The training of operation management includes the simulation of production planning department, enterprise purchasing department and enterprise human resource department and other courses, these courses consist of production planning department manager, project manager, workshop manager, enterprise management department, business administration department, human resources department, human resources assistant and other position simulations. Through this module, we can make the students experience the functions of product decision, purchasing, production, sales, inventory, financial, human resource management and so on and master the production planning, the writing of all kinds of forms, the analysis of inventory information, personnel recruitment, the preparation and analysis of all kinds of reports. Students will be trained to master comprehensive coordinating ability.

Marketing training module .The module includes training courses in marketing, electronic commerce, international trade practice and settlement. The courses include marketing environment analysis, marketing strategy, product strategy, price strategy, channel strategy, promotion strategy, commodity management, classification management, user management, information management, shopping management, international trade, transportation, foreign exchange, collection and documentation, examination of documents, preparing documents in letters of credit and other experimental projects. Training according to the analysis of the real case, let the student through the sand table. Analyze the whole marketing process, and make the marketing strategies. On the one hand, carry out quantitative tools of analysis and evaluation, put the strategic marketing management knowledge and skills into the simulation training, and make training students to comprehend the impotence of "know your enemy and yourself "On the other hand, build the common perception of sales strategy in the team, unify sales language and obtain abilities to solve the plight of the sales.

\section{The practice of enterprises founded and operated}

The module includes ERP enterprise sand table simulation and enterprise operation and competition Simulation courses, including simulated operation process, production management, marketing management, enterprise strategy management, enterprise raw material procurement management, enterprise production and management, enterprise financial management, competitor analysis and other experimental projects . In the business environment of virtual enterprise business, through simulation management, confrontation exercise, lecturer assessment, student awareness and a series of training links, students can combine the theoretical knowledge with Simulation of business activities, so that make students comprehend the rules of scientific management in the analysis of the market, develop strategies, marketing planning, organization and production, financial management and other activities. Students also be trained team spirit, innovation and entrepreneurial ability, improve management skills.

Modern enterprise business operations comprehensive virtual simulation module design. This module is a comprehensive practice platform, showed through the integration of modern enterprise business operations. The module is integrated with kinds of professional knowledge system, and shows the enterprise's real organization, work tasks, business process and operating environment, so that students can base on real business information platform for business. Results is main for innovation, and the process and operations are the main for entrepreneurship. Practice platform design not only close to the real business environment, but also students can fill in various forms virtually and witness various business processes and approval process. In this module, students will be trained to master the ability including implement comprehensive ability, integrated decision-making ability and innovation ability which is needed by management, students will be trained to have the global awareness and professional quality.

Virtual simulation experiment teaching platform design.Virtual simulation experiment teaching center of modern enterprise business operations consists of experimental teaching resources platform, teaching management platform and network information platform.

Experimental teaching resource platform. Experimental teaching resources platform consists of professional training platform, the practice of enterprises founded and operated platform and modern 
enterprise business operations comprehensive practice platform. Experimental teaching resource platform uses 3D technology and network technology, combined with the center of large data storage and database, through the platform selection and free combination of experimental projects. Students use computer to complete all kinds of virtual experimental resources configuration and use.At the same time, combined with the center real experiment scene, students complete the training task in real time, to achieve the established objectives and teaching effect. The platform also has the functions of information dissemination, data collection and analysis, interactive communication, performance evaluation, and the results show.

\section{Construction effect}

Center and enterprise commonly design and create the modern enterprise business operations comprehensive practice platform, which has been successful used in Heilongjiang foreign language school, Career Academy in Heilongjiang. And through the organization of university open class, more schools and students share the platform construction. Jilin Business and Technology College selected some teachers in the center to carry out the company created and operation practice, several visits after learning, the success of our school practice teaching mode is applied in the practice teaching of their school, and achieved good results. Our school will continue to strengthen the construction of experimental resources sharing platform, through a variety of ways to promote the application and sharing of central teaching resources, and achieving the province to share, demonstration, radiation international. In this way, we can fully adapt to the current economic and social development, leading the new situation in the reform and development of experimental teaching.

\section{Acknowledgements}

This work is supported by Heilongjiang Provincial Social Science Fund Project "Research on the Construction of Heilongjiang Province Financial Sharing Platform Based on the Perspective of Blockchain Technology" (18JYE672). Heilongjiang Province Educational Science Planning Subject"Comprehensive evaluation research on national experimental teaching demonstration center" (GBE1317011).

\section{References}

[1] Zhang Liucheng.Application Prospect of Block Chain Technology in Accounting Industry,2018 International Conference on Mechatronics Engineering and Computer Sciences(ICMECS 2018). IEEE, 2018:559-562.

[2] Zhang Liucheng,Chen Meizhi. The analysis of the deep processing industry of agricultural products and strategy in Heilongjiang Province,2018 International Conference on Mechatronics Engineering and Computer Sciences(ICMECS 2018). IEEE,2018:568-572.

[3] Zhang Liucheng. Impact of Block-Chain Technology on Auditing,2018 International Conference on Mechatronics Engineering and Computer Sciences(ICMECS 2018). IEEE,2018:573-577.

[4] Zhang Liucheng. Data Reliability Research on Accounting Information System Based on Block Chain Technology,2018 International Conference on Mechatronics Engineering and Computer Sciences(ICMECS 2018). IEEE,2018:604-607.

[5] Zhang Liucheng.Application And Analysis Of Witkey Mode In Network Economy[J]. Advances in Social Science, Education and Humanities Research, 2015(31), pp. 178-181

[6] Zhang Liucheng.The Research and Innovation of Witkey Mode under the New Era[J]. Advances in Education Research, 2015(11), pp. 102-105.

[7] Zhang Liucheng.Research on the problems of the application of XBRL financial statement in 
small and medium sized enterprises[J]. Advances in Social Science, Education and Humanities Research, 2016(59), pp. 1421-1424 